\title{
Liver Function in Areas of Hepatic Venous Congestion After Hepatectomy for Liver Cancer: 99mTc-GSA SPECT/CT Fused Imaging Study
}

\author{
MORIKATSU YOSHIDA ${ }^{1,2}$, TORU BEPPU ${ }^{3,4}$, SHINYA SHIRAISHI $^{2}$, NORIKO TSUDA $^{2}$, \\ FUMI SAKAMOTO ${ }^{2}$, KUNITAKA KURAMOTO $^{3,4}$, HIROHISA OKABE ${ }^{3}$, HIDETOSHI NITTA $^{3}$, \\ KATSUNORI IMAI ${ }^{3}$, SEIJI TOMIGUCHI ${ }^{5}$, HIDEO BABA ${ }^{3}$ and YASUYUKI YAMASHITA ${ }^{2}$ \\ ${ }^{1}$ Department of Radiology, Amakusa Medical Center, Amakusa, Japan; \\ ${ }^{2}$ Department of Diagnostic Radiology, Graduate School of Life Sciences, Kumamoto University, Kumamoto, Japan; \\ ${ }^{3}$ Department of Gastroenterological Surgery, Graduate School of Life Sciences, \\ Kumamoto University, Kumamoto, Japan; \\ ${ }^{4}$ Department of Surgery, Yamaga City Medical Center, Yamaga, Japan
}

\begin{abstract}
Background/Aim: The sacrifice of a major hepatic vein can cause hepatic venous congestion (HVC). We evaluated the effects of $H V C$ on regional liver function using the liver uptake value (LUV), that was calculated from ${ }^{99 \mathrm{~m}}$ Tc-labeled-galactosyl-human-serum-albumin $\quad\left({ }^{99 \mathrm{~m}} T \mathrm{Tc}\right.$ GSA) single-photon emission computed tomography (SPECT) /contrast-enhanced computed tomography (CE-CT) fused images. Patients and Methods: Sixty-two patients underwent ${ }^{99 \mathrm{~m}} T \mathrm{C}$-GSA SPECT/CE-CT prior to hepatectomy for liver cancer and at 7 days after surgery were divided into groups with $(n=8)$ and without HVC $(n=54)$. In the HVC group, $C T$ volume (CTV) and LUV were separately calculated in both congested and non-congested areas. Results: The remnant LUV/CTV of the HVC group was significantly smaller than that of the non-HVC group $(p<0.01)$. The mean functional ratio was $0.47 \pm 0.05$, and all ratios were $\geq 0.39$. Conclusion: After hepatectomy with sacrifice of major hepatic vein, liver function per unit volume in the congested areas was approximately $40 \%$ of that in the non-congested areas.
\end{abstract}

Hepatic venous congestion (HVC) often seems to be related to extended right and left hepatectomy when sacrificing the

Correspondence to: Morikatsu Yoshida, MD, Ph.D., Department of Radiology, Amakusa Medical Center, 854-1 Jikiba, Kamegawa, Amakusa, Kumamoto, Japan. Tel: +81 969244111, Fax: +81 969234086, e-mail: y_morikatsu@hotmail.com

Key Words: Hepatic venous congestion, ${ }^{99 \mathrm{~m} T c-l a b e l e d-g a l a c t o s y l-}$ human-serum-albumin SPECT/CE-CT fused image, liver uptake value, hepatic function, liver failure. middle hepatic vein and venous congestion has been observed in the left medial or right anterior sector of the remnant liver, respectively $(1,2)$. Contrast-enhanced computed tomography (CE-CT) imaging is clinically useful in the diagnosis of postoperative HVC (3). The negative impact of HVC has been reported in morphological regeneration after hepatectomy (1, 4-6). However, the liver volume cannot directly represent hepatic functional change itself $(7,8)$. Thus, the liver volume measured from CT (CTv) alone is not completely adequate for assessing the overall effects of $\mathrm{HVC}$ on hepatic functional recovery after hepatectomy.

${ }^{99 \mathrm{~m}} \mathrm{Tc}$-Labeled galactosyl human serum albumin $\left({ }^{99 \mathrm{~m}} \mathrm{Tc}-\right.$ GSA) scintigraphy has been used for the quantitative assessment of preoperative liver functional volume for patients with liver cancer (9-12). Moreover, the indices obtained by ${ }^{99 m}$ Tc-GSA single-photon emission computed tomography (SPECT) have been proven useful in evaluating the hepatic function during the regeneration process (9). Quantitative indices of liver uptake value (LUV) obtained by the combination of ${ }^{99} \mathrm{~m}$ Tc GSA SPECT and CT images have yielded an accurate estimation of the hepatic function and histopathological damage in patients with chronic liver disease (13). We crafted a ${ }^{99 \mathrm{~m}}$ Tc-GSA SPECT and CE-CT fused imaging technique using SPECT and a multi-detector row CT integrated system, which is now commercially available $(8,14,15)$. The registration between ${ }^{99 \mathrm{~m}} \mathrm{Tc}-\mathrm{GSA}$ SPECT and CE-CT images is considered to be satisfactory, and able to estimate the remnant liver function and the congested area precisely based on the LUV.

In HVC, remnant hepatocytes are regarded as compensating for the functional loss during the initial stages after hepatectomy (16-18). However, little is known regarding the exact nature of the effects of $\mathrm{HVC}$ on the 
regional and remnant hepatic functions. The aim of the present study was to clarify the impact of HVC on regional and remnant hepatic functions using the ${ }^{99 \mathrm{~m}} \mathrm{Tc}-\mathrm{GSA}$ SPECT/CE-CT fused imaging technique.

\section{Patients and Methods}

Between January 2011 and December 2014, 333 patients underwent 99mTc-GSA SPECT/CE-CT examinations for the perioperative evaluation of hepatectomy, mainly for liver cancer. We selected the patients who underwent segmentectomy or more and performed 99mTc-GSA SPECT/CE-CT examinations on them prior to surgery and then again at 7 days after surgery. The presence or absence of a congested area was assessed using the method described below. The primary endpoint was a comparison of liver function per unit volume in the congested and non-congested areas. Secondary endpoints included the influence of HVC on postoperative liver function and the postoperative course. Blinded evaluation of functional scintigraphic and functional CE-CT imaging was performed by separate radiologists/nuclear medicine physicians (M.Y. and S.S.). Based on the hepatic function on postoperative day 7 and the criteria established by the International Study Group of Liver Surgery (19), we determined whether postoperative liver failure actually occurred in these patients. Data were prospectively collected. This study was approved by our Institutional Review Board (approval number: 1383), and informed consent was obtained from all patients.

Liver resection. Liver resection was performed using our previously described techniques $(15,20)$. A suitable extent of liver resection was selected according to the indocyanine green (ICG) retention rate at $15 \mathrm{~min}$ (ICG R15) and functional volumetry by $99 \mathrm{~m} \mathrm{Tc}-\mathrm{GSA}$ SPECT/CE-CT images (21). If the estimated congested area was extensive, then venous preservation or reconstruction was planned.

Detection of HVC. Hepatic regions drained by hepatic vein tributaries were calculated on the basis of preoperative CE-CT imaging using the Ziostation2 workstation (ZIOSOFT, Tokyo, Japan). In previous studies $(3,4)$. HVC has been recognized as the attenuation difference area on arterial and hepatic portal phase CT images (Figure 1). We confirmed that the hepatic attenuation difference area calculated from postoperative CE-CT imaging obtained on postoperative day 7 was the same as the hepatic vein tributaries calculated from preoperative CE-CT imaging on the workstation. Patients were divided into two groups: the group with congestion who had definite postoperative HVC and the non-HVC group who did not have postoperative HVC.

$C T$ volumetry. The region of interest was manually set for the whole liver on each image of every slice; regions without any tumors were included $(8,20)$. We measured the whole liver and simulated remnant $\mathrm{CTv}$ from preoperative CE-CT images and the remnant CTv from postoperative CE-CT images. Moreover, in the HVC group, the simulated remnant volumes of the congested and non-congested areas were also measured on the basis of the surgical procedure and hepatic portal/venous tributaries from preoperative CE-CT imaging.

Functional volumetry by ${ }^{99 m} T c-G S A$ scintigraphic imaging. A SPECT/CT system was used for scintigraphy and CT imaging, respectively (22). ${ }^{99} \mathrm{mTc}-\mathrm{GSA}(185 \mathrm{MBq})$ was injected as a bolus
Table I. Image parameters of hepatic single-photon emission computed tomography (SPECT) imaging.

\begin{tabular}{lc}
\hline SPECT CT system & Symbia T16 \\
Scan state & 20 in after injection \\
Collimator & $140.0 \mathrm{keV} \pm 10 \%$ \\
Energy & $128 \times 128$ \\
Matrix & Low-medium energy general purpose \\
& 60 Steps of $15 \mathrm{~s} / \mathrm{step}, 360^{\circ}$ \\
Reconstruction & OS-EM algorithm $(3$ iterations, 8 subsets $)$ \\
Attenuation correction & Based on CT-derived attenuation-coefficient map \\
Collimator distance \\
response correction
\end{tabular}

into an antecubital vein. The image parameter of SPECT image is summarized in Table I. The attenuation-corrected SPECT and CT images were analyzed using a dedicated workstation (Ziostation2; ZIOSOFT, Tokyo, Japan). Whole-liver and simulated remnant LUVs were calculated from the preoperative ${ }^{99 \mathrm{~m} T c-G S A ~ S P E C T / C E-C T ~}$ images, and the remnant LUV was obtained from the postoperative 99mTc-GSA SPECT/CE-CT images (8). Moreover, in the HVC group, we calculated the simulated LUV of the congested and noncongested areas on the basis of the surgical procedure and hepatic portal/venous tributaries from preoperative CE-CT imaging. According to the attenuation difference on postoperative CE-CT images, we separately measured the LUV of these areas. To evaluate apparent effects of HVC on regional function, the LUV/CTV was calculated using pre-and postoperative $99 \mathrm{~m} \mathrm{Tc}-\mathrm{GSA}$ SPECT/CE-CT images. Furthermore, in the HVC group, the LUV/CTv of the congested and non-congested areas were independently measured. Finally, we calculated the functional ratio between the congested and non-congested areas using the following formula:

Functional ratio $=(\mathrm{LUV} / \mathrm{CTv}$ of congested area $) /(\mathrm{LUV} / \mathrm{CTV}$ of noncongested area)

Statistical analysis. Values are expressed as mean \pm standard deviation (range). To examine variations in the parameters within any two groups, a two-way analysis of variance in multiple comparisons was used. Values between any two groups were compared using the Mann-Whitney $U$-test, and correlations were analyzed using the Pearson test. Statistical analysis was performed using the JMP statistical software package (version 11; SAS, Cary, NC, USA). $p$-Values of less than 0.05 were considered statistically significant.

\section{Results}

Initially, out of the 333 patients, 65 who underwent segmentectomy or more were selected. A total of 11 patients were diagnosed as having impaired blood flow; however, three patients were excluded because they had accidental congestion in the remnant liver. They experienced partial outflow block with or without inflow block. Finally, 62 patients were divided into two separate groups: an HVC group comprising eight patients in whom the trunk of the 
A

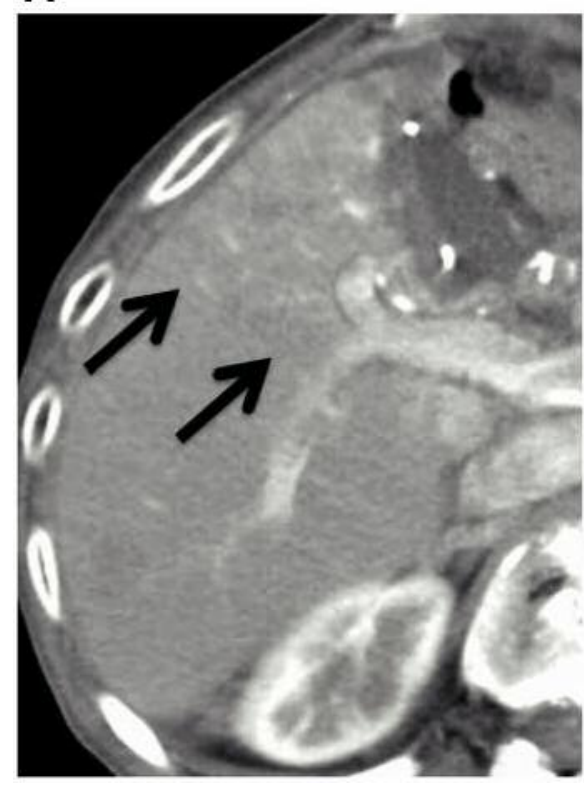

B

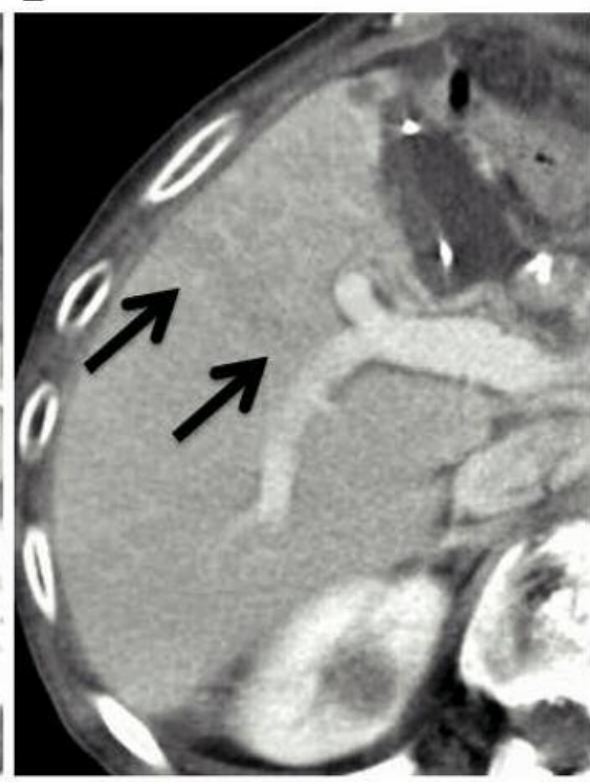

C

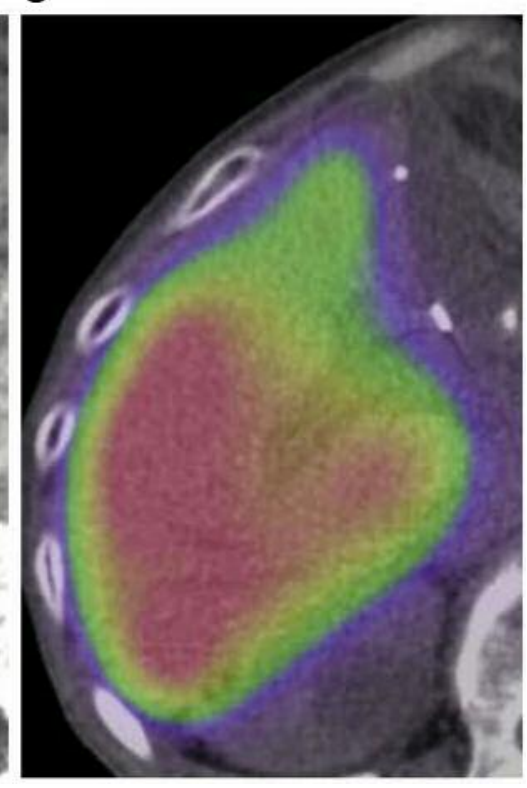

Figure 1. Patient 1 underwent extended left hepatectomy (S5). In the arterial (a) and portal (b) phases, venous congestion is seen in the anterior section. On ${ }^{99 m}$ Tc-labeled-galactosyl-human-serum-albumin $\left({ }^{99 m} T c\right.$-GSA) single-photon emission computed tomography (SPECT)/contrast-enhanced computed tomography $(C E-C T)$ fused imaging $(c)$, radioactivity was lower in the congested area than that in the non-congested area.

main hepatic vein had been sacrificed and the non-HVC group comprising 54 patients without transection of the main hepatic vein trunk. A typical case with HVC is shown in Figure 1. The perioperative clinical characteristics of patients are summarized in Table II. In the HVC group, six out of the eight patients had hepatocellular carcinoma (HCC), one had intrahepatic cholangiocarcinoma, and one had a large hemangioma. In the non-HVC group, 41 out of the 54 patients had HCC, seven had liver metastasis, five had intrahepatic cholangiocarcinoma, and one had a large hemangioma. Segmentectomy, monosectionectomy, and disectionectomy or more were performed on two, none, and six patients in the HVC group and two, 26, and 26 patients in the non-HVC group, respectively. There were no statistical differences in the preoperative hepatic functional tests, hepatic fibrosis, and surgical insult between the two groups.

Effects of HVC on regional hepatic functional volume. In the HVC group, the simulated CTV of the congested and noncongested areas before hepatectomy was $172.1 \pm 70.7 \mathrm{cc}$ and $711.6 \pm 210.2 \mathrm{cc}$, respectively, and $124.9 \pm 60.7 \mathrm{cc}$ and $837.1 \pm 231.4 \mathrm{cc}$, respectively, after hepatectomy. Before hepatectomy, the LUV/CTV of the HVC and non-HVC groups was $0.043 \pm 0.017 \% / \mathrm{m} 2 / \mathrm{cc}$ and $0.043 \pm 0.012 \% / \mathrm{m} 2 / \mathrm{cc}$, respectively, but the differences were not significant $(p=0.96)$.

After hepatectomy, the remnant LUV/CTv of the nonHVC group was $0.052 \pm 0.018 \% / \mathrm{m}^{2} / \mathrm{cc}$. In the HVC group,
LUV/CTV of the congested and non-congested areas was $0.029 \pm 0.008 \% / \mathrm{m}^{2} / \mathrm{cc}$ and $0.050 \pm 0.019 \% / \mathrm{m}^{2} / \mathrm{cc}$, respectively (Figure 2). There were no significant differences between the remnant LUV/CTV of the non-HVC group and that of non-congested areas in the HVC group $(p=0.96)$. In contrast, the remnant LUV/CTv of the congested areas was significantly smaller than that of the non-HVC group $(p<0.01)$. The remnant LUV/CTV of the congested areas was smaller than that of the non-congested areas, but the difference was not significant $(p=0.07)$. The functional ratio was $0.47 \pm 0.05$, and all of the recorded data were $\geq 0.39$ (Figure 3).

Postoperative liver failure. There were no surgery-related deaths within the 3 months after the surgery. According to the criteria (24), on postoperative day 7, 16 out of the 62 patients experienced postoperative liver failure, including three $(38 \%)$ out of the eight patients and $13(24 \%)$ out of the 54 patients in the HVC and non-HVC groups, respectively. In the $\mathrm{HVC}$ group, one patient had grade $\mathrm{A}$, one had grade $\mathrm{B}$, and one had grade $\mathrm{C}$ postoperative liver failure. In the non-HVC group, nine patients had grade A, three had grade $\mathrm{B}$, and one had grade $\mathrm{C}$ postoperative liver failure. The frequency of all grade liver failure was similar in both groups $(p=0.22)$, whereas that of grades $\mathrm{B}$ and $\mathrm{C}$ was higher in the HVC group than in the non-HVC group, but the difference was not significant $(p=0.24)$. 


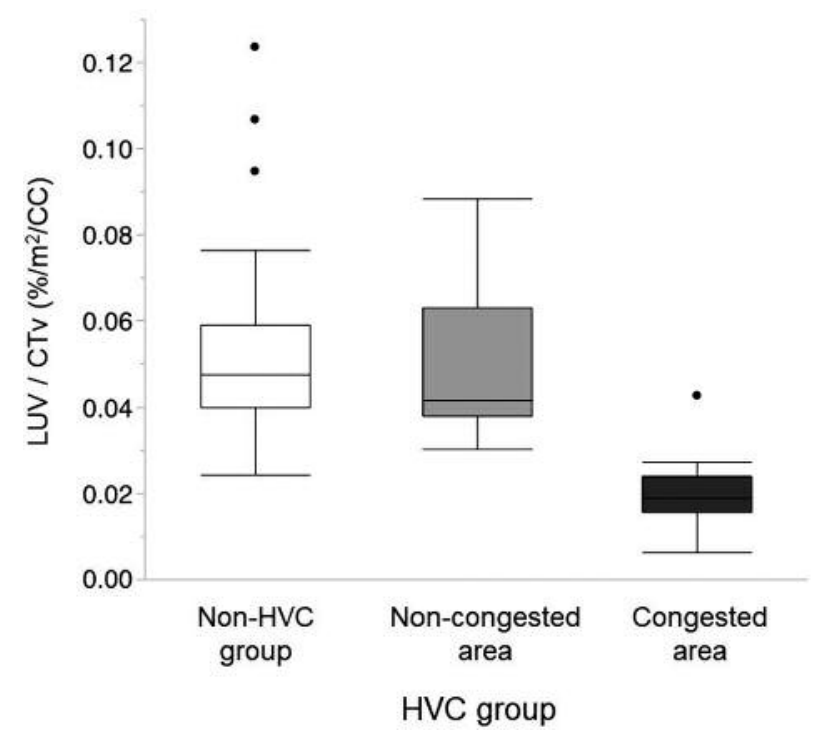

Figure 2. Liver uptake value (LUV)/liver volume measured from CT (CTv) of the groups with and without hepatic venous congestion (HVC) on postoperative day 7. No significant differences were observed between the remnant LUV/CTV of the non-HVC group $\left(0.052 \pm 0.018 \% / \mathrm{m}^{2} / \mathrm{cc}\right)$ and that of non-congested areas $\left(0.050 \pm 0.019 \% / \mathrm{m}^{2} / \mathrm{cc}\right)$ in the HVC group $(p=0.96)$. On the other hand, the remnant LUV/CTV of the congested areas $\left(0.029 \pm 0.008 \% / \mathrm{m}^{2} / \mathrm{cc}\right)$ in $H V C$ was significantly smaller than that of the non-HVC group $(p<0.01)$ and was also smaller than that of the noncongested areas in $H V C$, but the difference was not significant $(p=0.07)$.

\section{Discussion}

In the present study, we focused on patients with planned HVC and estimated the liver function of the congested area was approximately $40 \%$ that of the non-congested area. Although the function of the congested area can be calculated using the $99 \mathrm{~m}$ Tc-GSA SPECT/CE-CT system, currently this system is not widely used. In contrast, in patients with planned HVC, future congestion volume is easily simulated before surgery as a perfusion area of the sacrificed hepatic vein from preoperative CE-CT imaging in the dedicated workstation. Considering that the functional ratio of the congested area was approximately $40 \%$ or more, it is immediately possible to calculate the limit of safe liver resection volume. If the liver function of the congested area is calculated as $0 \%$, then the remnant liver function can be estimated to be smaller than actual liver function.

In congested areas, the venous blood was regurgitated to the portal vein through the sinusoid and portal blood supply was reduced $(3,25)$. In a completely congested area, the blood can flow into the hepatic artery and out of the portal vein, instead of the hepatic vein (25). Decreased GSA uptake in the congested area is caused by a decrease in the portal blood supply. The degree of HVC might be related to that of

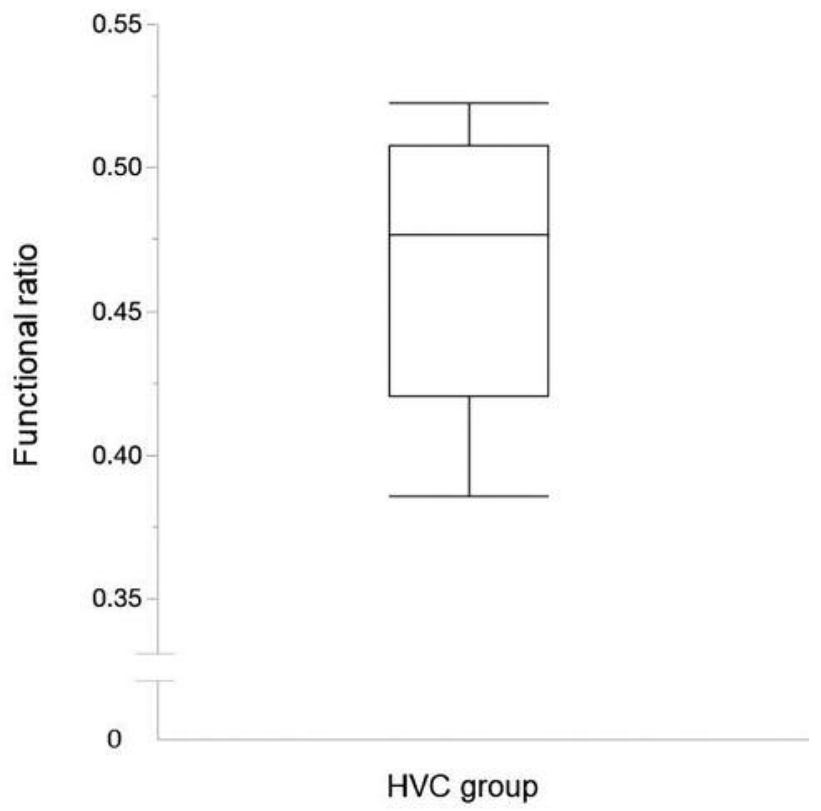

Figure 3. Distribution of functional ratios in the group with hepatic venous congestion $(H V C)(n=8)$. The bottom and top of the box show the first and third quartiles, and the band inside the box is the median. The median of the functional ratio was 0.47. The end whiskers show the lowest and highest points of the entire spectrum (0.39-0.52).

hepatic dysfunction at the very early postoperative stages. Moreover, the congested area can develop venous collaterals into the remnant hepatic venous system during the course of postoperative regeneration (25). In this study, the functional ratio was distributed within a narrow range of 0.39-0.52.

On intra-operative ICG fluorescence imaging, Kawaguchi et al. found the hepatic function in the congested areas in HVC was reduced to $40 \%$ compared with that in the non-congested areas (26). This imaging modality can evaluate the liver function of the congested area in HVC immediately after hepatic vein occlusion. Surprisingly, their functional ratio of $40 \%$ for the congested area was identical to that of our study. ICG fluorescence imaging was difficult to perform before hepatectomy and was captured only on the liver surface in their study, whereas ${ }^{99 m}$ Tc-GSA SPECT/CE-CT can be performed before hepatectomy and can evaluate the entire liver. We recommend that these two methods be used in a complementary manner. In contrast, upon using gadolinium-ethoxybenzyl-diethylenetriamine penta-acetate magnetic resonance imaging (EOB-MRI), the hepatic function in the congested segment was reduced to $70 \%$ compared with that in the non-congested segment (27). In that study, the liver to muscle ratio was compared between 
Table II. Clinical characteristics of all patients $(n=62)$.

\begin{tabular}{|c|c|c|c|c|}
\hline Characteristic & All patients & HVC group $(\mathrm{n}=8)$ & Non-HVC group $(\mathrm{n}=54)$ & $p$-Value \\
\hline Etiology: B: C: non B and non $\mathrm{C}$ hepatitis & $16: 14: 32$ & $1: 3: 4$ & $15: 11: 28$ & 0.46 \\
\hline Malignant tumor: HCC: non HCC & $47: 15$ & $6: 2$ & $41: 13$ & 0.95 \\
\hline Tumor volume (cc) & $165.0 \pm 302.5$ & $409.7 \pm 698.8$ & $132.4 \pm 198.0$ & 0.03 \\
\hline Gender: $\mathrm{M}: \mathrm{F}$ & $48: 14$ & $7: 1$ & $41: 13$ & 0.47 \\
\hline Age (years) & $68.9 \pm 9.6$ & $70.4 \pm 8.8$ & $67.5 \pm 9.8$ & 0.43 \\
\hline Surgical procedure: minor: major & $30: 32$ & $2: 6$ & $28: 26$ & 0.16 \\
\hline Child-Pugh score: 5:6:7 & $59: 2: 1$ & 8:0:0 & $51: 2: 1$ & 0.79 \\
\hline ICG R15 (\%) & $10.5 \pm 5.5$ & $12.3 \pm 6.2$ & $10.1 \pm 5.7$ & 0.32 \\
\hline Albumin $(\mathrm{g} / \mathrm{dl})$ & $4.2 \pm 0.4$ & $4.2 \pm 0.5$ & $4.2 \pm 0.4$ & 0.88 \\
\hline Total bilirubin (mg/dl) & $0.94 \pm 0.35$ & $0.82 \pm 0.14$ & $0.96 \pm 0.38$ & 0.32 \\
\hline AST (IU/l) & $38.4 \pm 21.9$ & $36.6 \pm 16.2$ & $38.6 \pm 22.9$ & 0.81 \\
\hline ALT (IU/l) & $41.6 \pm 37.2$ & $28.0 \pm 13.1$ & $43.9 \pm 39.5$ & 0.27 \\
\hline Total cholesterol (mg/dl) & $190.5 \pm 34.1$ & $175.8 \pm 37.8$ & $192.7 \pm 33.5$ & 0.26 \\
\hline Cholinesterase $(\mathrm{U} / \mathrm{l})$ & $262.1 \pm 62.9$ & $261.4 \pm 57.0$ & $262.2 \pm 64.4$ & 0.97 \\
\hline Platelet count $\left(\times 10^{4} / \mathrm{mm}^{3}\right)$ & $17.7 \pm 6.3$ & $18.0 \pm 8.1$ & $17.6 \pm 6.1$ & 0.89 \\
\hline Prothrombin time $(\%)$ & $100.3 \pm 18.9$ & $100.9 \pm 9.2$ & $100.2 \pm 20.1$ & 0.93 \\
\hline Whole liver CTv (cc) & $1266.1 \pm 274.5$ & $1313.7 \pm 363.2$ & $1274.6 \pm 270.6$ & 0.57 \\
\hline Simulated remnant CTv (cc) & $873.7 \pm 246.6$ & $851.2 \pm 185.4$ & $872.8 \pm 246.4$ & 0.83 \\
\hline Whole liver LUV $\left(\% / \mathrm{m}^{2}\right)$ & $48.5 \pm 8.4$ & $45.3 \pm 8.6$ & $48.9 \pm 8.2$ & 0.20 \\
\hline Simulated remnant LUV $\left(\% / \mathrm{m}^{2}\right)$ & $34.5 \pm 8.1$ & $35.4 \pm 7.2$ & $34.9 \pm 8.1$ & 0.88 \\
\hline \multicolumn{5}{|l|}{ Hepatic fibrosis score: } \\
\hline F0-2: F3-4 & $42: 20$ & $7: 1$ & $35: 19$ & 0.20 \\
\hline Blood loss (cc) & $988.1 \pm 1984.3$ & $975.2 \pm 488.1$ & $989.5 \pm 2088.3$ & 0.98 \\
\hline Operative time ( $\min$ ) & $421.4 \pm 130.1$ & $498.3 \pm 143.9$ & $412.9 \pm 127.1$ & 0.13 \\
\hline
\end{tabular}

HVC, Hepatic venous congestion; HCC, hepatocellular carcinoma; ICG R15, indocyanine green retention rate at 15 min; AST, aspartate aminotransferase; ALT, alanine aminotransferase; CTv, liver volume measured from CT; LUV, liver uptake value measured by $99 \mathrm{~m}$ Tc-labeledgalactosyl-human-serum-albumin (99mTc-GSA) single-photon emission computed tomography (SPECT) /contrast-enhanced computed tomography (CE-CT); F scores, degree of hepatic fibrosis according to the new Inuyama classification (23).

Table III. Hepatic functional indices of the group with hepatic venous congestion before hepatectomy.

\begin{tabular}{|c|c|c|c|c|c|c|c|}
\hline \multirow[t]{2}{*}{$\begin{array}{l}\text { Patient } \\
\text { number }\end{array}$} & \multirow[t]{2}{*}{$\begin{array}{c}\text { Surgical } \\
\text { procedure }\end{array}$} & \multirow[t]{2}{*}{$\begin{array}{l}\text { Sacrificed } \\
\text { vein }\end{array}$} & \multirow[t]{2}{*}{$\begin{array}{l}\text { Congested } \\
\text { area }\end{array}$} & \multirow[t]{2}{*}{$\begin{array}{l}\text { Postoperative } \\
\text { liver failure }\end{array}$} & \multirow[t]{2}{*}{$\begin{array}{c}\text { LUV/CTV on } \\
\left(\% / \mathrm{m}^{2} / \mathrm{cc}\right)\end{array}$} & \multicolumn{2}{|c|}{$\begin{array}{l}\text { Functional } \\
\text { ratio }\end{array}$} \\
\hline & & & & & & $\begin{array}{c}\text { Congested } \\
\text { area }\end{array}$ & $\begin{array}{c}\text { Non-congested } \\
\text { area }\end{array}$ \\
\hline 1 & Ex-left & Middle & Anterior & None & 0.043 & 0.088 & 0.48 \\
\hline 2 & Ex-left & Middle & Anterior & $\mathrm{B}$ & 0.019 & 0.042 & 0.45 \\
\hline 3 & Ex-right & Middle & Medial & $\mathrm{C}$ & 0.027 & 0.071 & 0.39 \\
\hline 4 & $\mathrm{~S} 1$ and $\mathrm{S} 8$ & Middle & Anterior & A & 0.019 & 0.040 & 0.47 \\
\hline 5 & Ex-right & Middle & Medial & None & 0.019 & 0.047 & 0.41 \\
\hline 6 & S8 & Middle & Anterior & None & 0.016 & 0.030 & 0.51 \\
\hline 7 & Ex-left & Middle & Anterior & None & 0.019 & 0.038 & 0.50 \\
\hline 8 & Ex-right & Middle & Medial & None & 0.024 & 0.046 & 0.52 \\
\hline Mean & & & & & $0.029 \pm 0.008$ & $0.050 \pm 0.019$ & $0.47 \pm 0.05$ \\
\hline
\end{tabular}

LUV, Liver uptake value; CTv, liver volume measured from computed tomography; Ex-right, extended right hepatectomy, ex-left, extended left hepatectomy.

non-congested area and whole HVC segment. The HVC segment included both congested and non-congested areas: therefore, the hepatic function was estimated to be better than actual liver function. Although EOB-MRI was useful for detecting the tumor, a functional assessment for preoperative simulation was not completely established (27, 28). By evaluating the clinical course, several reports have confirmed that ${ }^{99 \mathrm{~m}} \mathrm{Tc}-\mathrm{GSA}$ SPECT/CT is useful for 
preoperative functional simulation and assessment of postoperative functional liver regeneration $(8,11,15)$.

In the HVC group, there was a relatively higher incidence of postoperative liver failure; therefore, HVC might be a factor responsible for this medical complication. Not much attention has been paid to the role of $\mathrm{HVC}$ at the time of preoperative decision making regarding liver resection. In this study period, we made minor changes to the extent of liver resection intraoperatively. Considering the relationship between HVC and portal blood supply, the effect of HVC on regional hepatic function might not be mild. Impaired portal blood supply substantially reduces regional hepatic function (7). The subsequent lack of portal blood supply impairs early postoperative liver function and regeneration of the liver remnant (4-6). In this study, three patients experienced liver failure. Considering the latent risks involved in hepatectomy, we recommend venous reconstruction or portal vein embolization in patients with an insufficient functional reserve $(29,30)$. In patients with noninvasive $\mathrm{HCC}$, the preservation of the hepatic vein is also possible.

There exist some limitations to the present study. Firstly, this was a retrospective study performed at a single academic center. The population included a small number of patients with HVC. Therefore, the results obtained need further confirmation by large multicenter studies. Secondly, the degree of HVC varied among cases on postoperative day 7 because of the degree of the formation of intrahepatic collaterals between obstructive and non-obstructive veins. Thirdly, we did not evaluate the relationship between HVC and other risk factors of postoperative liver failure, such as preoperative chemotherapy, blood transfusion, postoperative complications, and postoperative external biliary drainage $(31,32)$. These may be related to both hepatic functional recovery and postoperative liver failure.

We conclude that hepatic function per unit volume in the congested areas was approximately $40 \%$ of that in the noncongested areas. For preoperative simulation, a more accurate estimation of the future remnant liver volume may be obtained by calculating the sum of the volume of the congested area multiplied by 0.4 and the volume of the noncongested area.

\section{Acknowledgements}

The Authors declare that they have no conflict of interest in regard to this study.

\section{References}

1 Lee S, Park K, Hwang S, Lee Y, Choi D, Kim K, Koh K, Han S, Choi K, Hwang K, Makuuchi M, Sugawara Y and Min P: Congestion of right liver graft in living donor liver transplantation. Transplantation 71: 812-814, 2001.
2 Kido $\mathrm{M}, \mathrm{Ku} \mathrm{Y}$, Fukumoto T, Tominaga M, Iwasaki T, Ogata S, Takenaga M, Takahashi M, Kuroda Y, Tahara S, Tanaka K, Hwang $S$ and Lee S: Significant role of middle hepatic vein in remnant liver regeneration of right-lobe living donors. Transplantation 75: 1598-1600, 2003.

3 Kim BS, Kim TK, Kim JS, Lee MG, Kim JH, Kim KW, Sung KB, Kim PN, Ha HK, Lee SG and Kang W: Hepatic venous congestion after living donor liver transplantation with right lobe graft: two-phase CT findings. Radiology 232: 173-180, 2004.

4 Akamatsu N, Sugawara Y, Kaneko J, Sano K, Imamura H, Kokudo $\mathrm{N}$ and Makuuchi M: Effects of middle hepatic vein reconstruction on right liver graft regeneration. Transplantation 76: 832-837, 2003.

5 Maema A, Imamura H, Takayama T, Sano K, Hui AM, Sugawara $\mathrm{Y}$ and Makuuchi M: Impaired volume regeneration of split livers with partial venous disruption: a latent problem in partial liver transplantation. Transplantation 73: 765-769, 2002.

6 Scatton O, Plasse M, Dondero F, Vilgrain V, Sauvanet A and Belghiti J: Impact of localized congestion related to venous deprivation after hepatectomy. Surgery 143: 483-489, 2008.

7 Beppu T, Hayashi H, Okabe H, Masuda T, Mima K, Otao R, Chikamoto A, Doi K, Ishiko T, Takamori H, Yoshida M, Shiraishi S, Yamashita $\mathrm{Y}$ and Baba $\mathrm{H}$ : Liver functional volumetry for portal vein embolization using a newly developed 99mTc-galactosyl human serum albumin scintigraphy SPECTcomputed tomography fusion system. J Gastroenterol 46: 938943, 2011.

8 Yoshida M, Shiraishi S, Sakamoto F, Beppu T, Utsunomiya D, Okabe H, Tomiguchi S, Baba H and Yamashita Y: Assessment of hepatic functional regeneration after hepatectomy using (99m)Tc-GSA SPECT/CT fused imaging. Ann Nucl Med 28: 780-788, 2014.

9 Kwon AH, Matsui Y, Ha-Kawa SK and Kamiyama Y: Functional hepatic volume measured by technetium-99m-galactosyl-human serum albumin liver scintigraphy: comparison between hepatocyte volume and liver volume by computed tomography. Am J Gastroenterol 96: 541-546, 2001.

10 Kira T, Tomiguchi S, Kira M, Ohyama Y and Takahashi M: Quantitative evaluation of the hepatic functional reserve using technetium-99m DTPA-galactosyl human serum albumin before and after transjugular intrahepatic portosystemic shunt. Eur J Nucl Med 24: 1268-1272, 1997.

11 Yumoto Y, Yagi T, Sato S, Nouso K, Kobayashi Y, Ohmoto M, Yumoto E, Nagaya I and Nakatsukasa H: Preoperative estimation of remnant hepatic function using fusion images obtained by $(99 \mathrm{~m}) \mathrm{Tc}-$ labelled galactosyl-human serum albumin liver scintigraphy and computed tomography. Br J Surg 97: 934-944, 2010.

12 Clavien PA, Petrowsky H, DeOliveira ML and Graf R: Strategies for safer liver surgery and partial liver transplantation. N Engl J Med 356: 1545-1559, 2007.

13 Yoshida M, Shiraishi S, Sakaguchi F, Utsunomiya D, Tashiro K, Tomiguchi S, Okabe H, Beppu T, Baba H and Yamashita Y: A quantitative index measured on $99 \mathrm{~m}$ Tc GSA SPECT/CT 3D fused images to evaluate severe fibrosis in patients with chronic liver disease. Jpn J Radiol 30: 435-441, 2012.

14 Beppu T, Nitta H, Hayashi H, Imai K, Okabe H, Nakagawa S, Hashimoto D, Chikamoto A, Ishiko T, Yoshida M, Yamashita Y and Baba H: Effect of branched-chain amino acid supplementation on functional liver regeneration in patients undergoing portal vein 
embolization and sequential hepatectomy: a randomized controlled trial. J Gastroenterol 50: 1197-1205, 2015.

15 Hayashi H, Beppu T, Okabe H, Kuroki H, Nakagawa S, Imai K, Nitta $\mathrm{H}$, Chikamoto A, Ishiko $\mathrm{T}$ and Baba $\mathrm{H}$ : Functional assessment versus conventional volumetric assessment in the prediction of operative outcomes after major hepatectomy. Surgery 157: 20-26, 2015.

16 Jochum C, Beste M, Penndorf V, Farahani MS, Testa G, Nadalin S, Malago M, Broelsch CE and Gerken G: Quantitative liver function tests in donors and recipients of living donor liver transplantation. Liver Transpl 12: 544-549, 2006.

17 Jansen PL, Chamuleau RA, van Leeuwen DJ, Schipper HG, Busemann-Sokole E and van der Heyde MN: Liver regeneration and restoration of liver function after partial hepatectomy in patients with liver tumors. Scand J Gastroenterol 25: 112-118, 1990.

18 Kobayashi T, Imamura H, Aoki T, Sugawara Y, Kokudo N and Makuuchi M: Morphological regeneration and hepatic functional mass after right hemihepatectomy. Digestive Surg 23: 44-50, 2006.

19 Rahbari NN, Garden OJ, Padbury R, Brooke-Smith M, Crawford M, Adam R, Koch M, Makuuchi M, Dematteo RP, Christophi C, Banting S, Usatoff V, Nagino M, Maddern G, Hugh TJ, Vauthey JN, Greig P, Rees M, Yokoyama Y, Fan ST, Nimura Y, Figueras J, Capussotti L, Büchler MW and Weitz J: Posthepatectomy liver failure: a definition and grading by the International Study Group of Liver Surgery (ISGLS). Surgery 149: 713-724, 2011.

20 Okabe H, Beppu T, Hayashi H, Mima K, Nakagawa S, Kuroki H, Imai K, Nitta H, Masuda T, Hashimoto D, Chikamoto A, Watanabe M, Ishiko T, Yoshida M, Yamashita Y and Baba H: Rank classification based on the combination of indocyanine green retention rate at $15 \mathrm{~min}$ and $(99 \mathrm{~m}) \mathrm{Tc}-\mathrm{DTPA}-$ galactosyl human serum albumin scintigraphy predicts the safety of hepatic resection. Nucl Med Commun 35: 478-483, 2014.

21 Beppu T, Ishiko T, Chikamoto A, Komori H, Masuda T, Hayashi H, Okabe H, Otao R, Sugiyama S, Nasu J, Horino K, Takamori H and Baba $\mathrm{H}$ : Liver hanging maneuver decreases blood loss and operative time in a right-side hepatectomy. Hepatogastroenterology 59: 542-545, 2012.

22 Yoshida M, Shiraishi S, Sakaguchi F, Utsunomiya D, Tashiro K, Tomiguchi S, Okabe H, Beppu T, Baba H and Yamashita Y: Fused 99m-Tc-GSA SPECT/CT imaging for the preoperative evaluation of postoperative liver function: Can the liver uptake index predict postoperative hepatic functional reserve? Jpn J Radiol 30: 255-262, 2012.

23 Ichida F, Tsujii $\mathrm{T}$ and Omata M: New Inuyama classification; new criteria for histological assessment of chronic hepatitis. Int Hepatol Commun 6: 112-119, 1996.

24 Skrzypczyk C, Truant S, Duhamel A, Langlois C, Boleslawski E, Koriche D, Hebbar M, Fourrier F, Mathurin P and Pruvot FR: Relevance of the ISGLS definition of posthepatectomy liver failure in early prediction of poor outcome after liver resection: study on 680 hepatectomies. Ann Surg 260: 865-870, 2014.
25 Sano K, Makuuchi M, Miki K, Maema A, Sugawara Y, Imamura $\mathrm{H}$, Matsunami $\mathrm{H}$ and Takayama T: Evaluation of hepatic venous congestion: proposed indication criteria for hepatic vein reconstruction. Ann Surg 236: 241-247, 2002.

26 Kawaguchi Y, Ishizawa T, Miyata Y, Yamashita S, Masuda K, Satou S, Tamura S, Kaneko J, Sakamoto Y, Aoki T, Hasegawa $\mathrm{K}$, Sugawara Y and Kokudo N: Portal uptake function in venoocclusive regions evaluated by real-time fluorescent imaging using indocyanine green. J Hepatol 58: 247-253, 2013.

27 Ninomiya M, Shirabe K, Kayashima H, Ikegami T, Nishie A, Harimoto N, Yamashita Y, Yoshizumi T, Uchiyama H and Maehara Y: Functional assessment of the liver with gadoliniumethoxybenzyl-diethylenetriamine penta-acetate-enhanced MRI in living-donor liver transplantation. Br J Surg 102: 944-951, 2015.

28 Morine Y, Enkhbold C, Imura S, Ikemoto T, Iwahashi S, Saito YU, Yamada S, Utsunomiya $\mathrm{T}$ and Shimada M: Accurate estimation of functional liver volume using Gd-EOB-DTPA MRI compared to MDCT/99mTc-SPECT fusion imaging. Anticancer Res 37: 5693-5700, 2017.

29 Mise Y, Hasegawa K, Satou S, Aoki T, Beck Y, Sugawara Y, Makuuchi M and Kokudo N: Venous reconstruction based on virtual liver resection to avoid congestion in the liver remnant. Br J Surg 98: 1742-1751, 2011.

30 Beppu T, Okabe H, Okuda K, Eguchi S, Kitahara K, Taniai N, Ueno S, Shirabe K, Ohta M, Kondo K, Nanashima A, Noritomi T, Okamoto K, Kikuchi K, Baba H and Fujioka H: Portal vein embolization followed by right-side hemihepatectomy for hepatocellular carcinoma patients: A Japanese multi-institutional study. J Am Coll Surg 222: 1138-1148, 2016.

31 Otao R, Beppu T, Isiko T, Mima K, Okabe H, Hayashi H, Masuda T, Chikamoto A, Takamori $\mathrm{H}$ and Baba H: External biliary drainage and liver regeneration after major hepatectomy. Br J Surg 99: 1569-1574, 2012.

32 Slankamenac K, Breitenstein S, Held U, Beck-Schimmer B, Puhan MA and Clavien PA: Development and validation of a prediction score for postoperative acute renal failure following liver resection. Ann Surg 250: 720-728, 2009.
Received February 22, 2018

Revised March 15, 2018

Accepted March 20, 2018 